\title{
MRS reports election results for 2018
}

\author{
www.mrs.org/governance
}

$\mathrm{M}$

embers of the Materials Rsearch

Society (MRS) have elected the 2018 vice president (who will serve as president in 2019) and five directors to join the 2018 MRS Board of Directors. The Board is composed of four elected officers and up to 18 board members, 15 of whom are elected by the membership. A fifth officer (treasurer) is appointed yearly.

The MRS Board of Directors is the highest governing body of MRS, responsible for establishing policy, monitoring progress of the Society toward its long-term goals, and setting the strategic directions for the major activities of the Society, including its meetings, publications, interactions with government agencies, and cooperative efforts with other professional societies throughout the world.

The officers of the Society are the president (who serves as chair of the Board), the vice president (who is also the president-elect), the secretary, the treasurer (a position appointed by the Board of Directors), and the immediate past president. All members of the Board, except the president, serve on one of seven Board Committees: Audit, External Relations, Finance, Governance, Nominating, Operational and Strategic Oversight, and Planning.

Terms of office expire at the end of the year indicated in parentheses. The asterisk $(*)$ designates those who are newly elected. The annual election ended August 31, 2017.

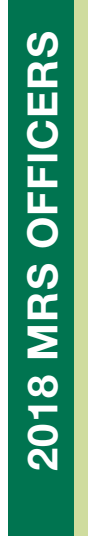

\section{President}

Sean J. Hearne

Sandia National Laboratories

Immediate Past President

Susan Trolier-McKinstry

Vice President (President-Elect)

* Michael Fitzsimmons

Oak Ridge National Laboratory

and The University of Tennessee
The Pennsylvania State University

\section{Secretary}

Eric A. Stach

University of Pennsylvania

Treasurer

David J. Parrillo

The Dow Chemical Company

Executive Director

Todd M. Osman

Materials Research Society
* Griselda Bonilla (2020)

IBM T.J. Watson Research Center

(2)

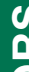

\section{Li-Chyong Chen (2019)}

National Taiwan University

Matt Copel (2018)

IBM T.J. Watson Research Center

Paul S. Drzaic (2018)

Apple, Inc.

Dawnielle Farrar-Gaines (2019)

Johns Hopkins University

Yury Gogotsi (2018)

Drexel University

Claudia E. Gutiérrez-Wing (2019)

Instituto Nacional de

Investigaciones Nucleares

Young-Chang Joo (2018)

Seoul National University
Lincoln J. Lauhon (2019)

Northwestern University

* Paul McIntyre (2020)

Stanford University

* Christopher A. Schuh (2020)

Massachusetts Institute

of Technology

* Rachel Segalman (2020)

University of California,

Santa Barbara

The University of Texas at Dallas

Molly M. Stevens (2019)

Imperial College London

* Ehrenfried Zschech (2020)

Fraunhofer Institute for Ceramic

Technologies and Systems
Magaly Spector (2018)

*Newly elected.

\section{The International Conference on Nanofilms 2018 to be held March 20-22} www.ecnf2018.org

The International Conference on

Nanofilms (ECNF) 2018 will be held March 20-22 in Cranfield, UK. The conference offers an opportunity to active researchers and industrialists to share the latest research and development work re- lated to coatings and nanofilms developed by a wide range of processing techniques, including atomic layer deposition, chemical vapor deposition, molecular beam epitaxy, plasma and thermal spray, physical vapor deposition (evaporation, cathodic arc, sputtering, high-power impulse magnetron sputtering, and pulsed laser deposition), and sol-gel. The chairman is Jose L. Endrino of Cranfield University.

The main topics of the conference are protective and tribological coatings; 